\title{
Study of ATD angle in epileptic patients- A parameter in palmar dermatoglyphics
}

\author{
Rashmi C Goshi \\ Assistant Professor, Dept. of Anatomy, JSS Medical College, Mysore, Karnataka, India \\ *Corresponding Author: \\ Email: rashmicgoshi@jssuni.edu.in
}

Received: $28^{\text {th }}$ December, 2017

Accepted: $21^{\text {st }}$ June, 2018

\begin{abstract}
Introduction: Dermatoglyphics is the study of quantitative and qualitative patterns of ridge in palms and soles. It is being investigated in diseases having genetic basis.

The recent evidence from adoption studies has provided a basis for the genetic contribution in generalized tonic clonic seizures. The parameter taken is ATD Angle and measured and compared between cases and controls.

Objectives: To study the ATD angle in palmar dermatoglyphic patterns in generalized tonic clonic seizure patients. To compare dermatoglyphic angle of cases with the normal population.

Materials and Methods: The ink method was followed to take palm prints. The palmar prints of 50 epileptic patients and 50 normal individuals of both sexes were collected for the study. ATD angle was measured and compared with normal.

Results: ATD angle is increased in both right and left hands of combined series of male and female epileptics and only in left hand of female epileptics which is statistically significant.

Interpretation and Conclusion: There is significant difference in the epileptic patients in various

dermatoglyphic features when compared to controls. One of them is with respect to ATD angle. Hence, it is possible to identify 'at risk' population with the help of dermatoglyphics.
\end{abstract}

Keywords: Dermatoglyphics, Epilepsy, ATD angle.

\section{Introduction}

The entire human body is covered with the most important and largest organ called skin. As we all know skin performs many vital functions in the life of an individual viz.., it protects and safeguards the body from the weather changes, it saves the internal organs of the body from injuries and also maintains the body temperature. However, the skin on the palmar aspect of hand and plantar aspect of foot is exclusively designed with corrugations which are due to ridges and configurations especially for the function of grasping without which the objects would easily slip away from the hands.

The scientific study of these dermal ridge configuration on the digits, palms and soles is dermatoglyphics. The term dermatoglyphics for the first time was coined by Cummins in 1926. Etmologically this term is harmonious blend of two words Derma means skin, glyphe means carve. It gives the impression that something has been carved out of the skin. It has been accepted and adapted internationally

These features of dermatoglyphics are formed during the 13th / 14th week of the developing foetus and once formed remain permanent and never change throughout the life except in the dimensions which commensurate with the growth of an individual. The scientific value of dermatoglyphics largely derives from this fact that dermal ridges appear in the third to 5th month of foetal development and the patterns then formed never change. ${ }^{1,3,8}$

The permanency of ridge patterns, the extreme variability from one individual to the other and easy analysis are some of the reasons for its wide application in a variety of conditions mainly with genetic etiology.

Abnormality in the genetic configurations of parents is inherited by children and is reflected in the dermatoglyphic pattern. Hence dermatoglyphic study proves to be a very useful, easily applicable, inexpensive, indispensable tool as an indicator in the diagnosis of hereditary diseases in patients.

The etiology of the epilepsies allows a classification of syndrome features into two groupsidiopathic or cryptogenic epilepsy, which has isolated primary symptoms without apparent cause and is probably hereditary and palm print configurations are inherited with an embryonic origin common to nervous system. Their attractions indicate pleiotropic effects of the genotype responsible for enaphalographic irregularity and convulsive seizures. , $^{5}$

Studies are also being done to know the existence of correlation between dermatoglyphics and leprosy, congenital heart diseases, pulmonary tuberculosis, bronchial asthama.

Dermatoglyphics is often claimed to be associated with several diseases like congenital heart disease (Alter and Schllenberg 1970), Schizophrenia (Bramon et al 2005), cancer (Abbasi et al 2006), genetic disorders. (Mukharjee

2007) and diabetes (Kumbani 2007). ${ }^{4,9}$

Hence the present study has been undertaken to find out the existence of any correlation between palmar dermatoglyphics (ATD Angle) of patients having generalized tonic clonic seizures (GTCS) and normal individuals and the data obtained testify to a 
certain diagnostical and prognostical value of dermatoglyphical features.

\section{Materials and Methods}

With the permission of Dean, Head of the Department and Ethical Committee approval from the college, the study was undertaken.

Source of Data: The patient diagnosed as generalised tonic clonic seizure attending medical services at chigateri general hospital and Bapuji hospital attached to JJM Medical College, Davangere were taken as cases. Equal number of age and sex matched individuals who have no medical and psychiatric illnesses, with no past history or family history of seizures served as controls The ATD angle of consecutive patients diagnosed as GTCS and controls were collected for the study.

Sample Size: 50 cases and 50 controls

Type of Study: Case Control Study

\section{Inclusion Criteria:}

1. Age between $15 \mathrm{y}$ to $60 \mathrm{y}$

2. Both male and female sex included

\section{Exclusion Criteria:}

1. Patients associated with other psychiatric illnesses

2. Patients associated with mental retardation

3. Patients with history of trauma and other medical illnesses

Materials Used: Kores quick drying duplicating ink, rubber roller, wooden roller, inking slab, cotton puff, spirit, scale, crystal bond paper, pencil, protracter, magnifying lens, soap, Towel.

\section{Methodology}

The palm of the individual's right and left hand was inked with the help of rubber roller. The ink was spread uniformly to rubber roller with the help of tile. The crystal bond paper was rolled forwards on to the wooden roller. The wrist of the palm was kept on the roller and it was rolled backwards by applying pressure on the zone of flexion creases at wrist, ulnar margin, flexion creases in central region of hand and over the knuckles. Thus the print appeared on the crystal bond paper. Soon after the print was taken the sheets were coded with Name, Age and Sex for Cases and Controls, and then subjected to detailed analysis. Statistical analysis include calculation of Mean, Standard deviation and application of Chi square test.

\section{Dermatoglyphic Configurations}

Ridge Detail (Minutiae): Epidermal ridges are having irregularities of direction, discontinuities and branching. Such characters are collectively termed minutiae or ridge characteristic.

The following terms are in general use to describe some common types:

Island: A small independent ridge, approximately circular in outline, sometimes called a point. Strictly, it contains only one sweat gland pore.
Short Ridge: A ridge which contains from two to five pores.

Fork: The bifurcation of a ridge, sometimes called a Y formation.

Enclosure: Any continuous ridge outline which surrounds a furrow. Commonly an enclosure is formed by two forks in opposition on the same ridge.

End: Termination of a ridge.

Interstitial Line: It is a narrow subsidiary ridge in the furrow between individual ridges. It is inconstant and omitted on ridge counting.

\section{Dermatoglyphic Landmarks}

The dermatoglyphic landmarks are type lines, cores and triradius or delta.

Type Lines: They are the innermost ridges that bound the pattern area. These ridges run parallel, then diverge or separate and tend to surround the pattern area of an impression. The type lines are appropriately termed as skeleton of the pattern. They are important for determining the location of delta.

Cores: They are the central part of the patterns. They may also be called as inner terminus of the patterns. The core can be a circle, an ellipse, a straight ridge, a hook shaped ridge or an island. If there is a rod like line in the centre, the midpoint is taken as core. In ridge counting, not the whole core but the point of core only is used.

Triradius or Delta: A triradius is defined as the centre of the delta shaped or deltoid junction of three regions, each containing curved streams of approximately parallel ridges i.e., three ridge systems. Geometrically, the triradial point should be the meeting place of three radiants which make angles of $120^{\circ}$ with one another and demarcate the three regions. Unless each of the angles between the radiants is $90^{\circ}$ or more, no triradius is deemed to exist. ${ }^{1,2}$

Axial Triradius: Axial triradius is located mostly near proximal margin of the palm, in the space between thenar and hypothenar eminences. Depending upon the level of position at which the axial triradius is present, it may be termed $t, t$ ' or $t$ ". An axial triradius at or very near the proximal margin is formulated as t.The most distally situated position of an axial triradius near the centre of palm is t" and when it lies at an intermediate position it is t'. The position of axial triradius may be displaced. If it is shifted towards the radial side, it is called t'. Most frequently it is displaced towards the ulnar side and labelled t". In extreme cases it may be found in the hypothenar region, nearer to ulnar border of palm; then it can be labelled as border triradius.

ATD Angle: It is the dermatoglyphic trait formed by drawing lines between the triradii below the first ' $a$ ' and last digit ' $d$ ' and the most proximal triradius on the hypothenar region of the palm (' $\mathrm{t}$ ').

The palm has been divided into several anatomically defined areas to carry out dermatoglyphic analysis. Triradius is the point of confluence from where the ridges usually radiate in three different 
directions. We see four digital triradii in the distal portions of palm. They are a, b, c, d in radio ulnar direction. The axial triradius" t" is found usually near the proximal palmar margin, close to palmar axis. a, $t, d$ triradii are joined and angle ATD is measured with the help of protractor. ${ }^{1,3}$

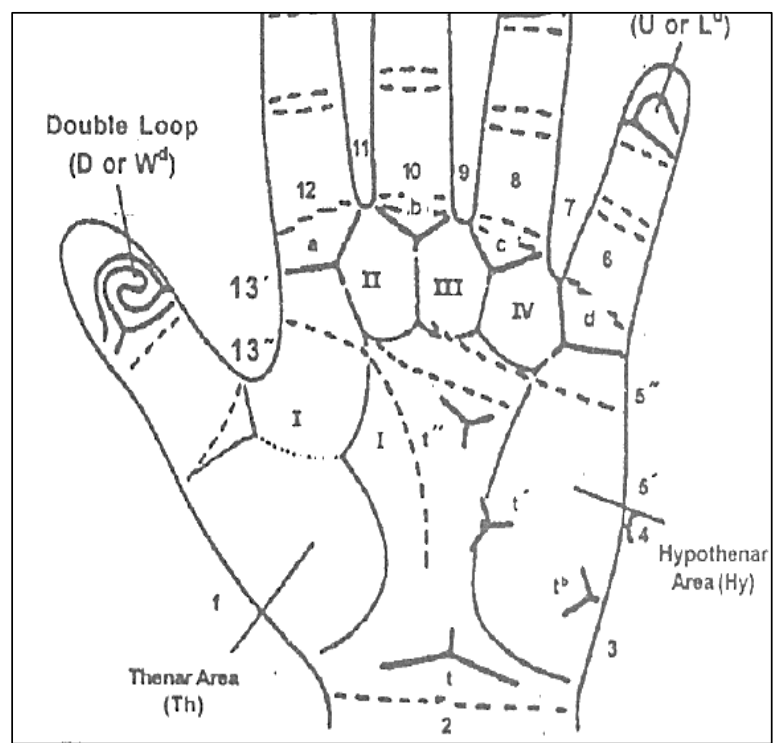

Fig. 1

\section{Results}

Observations were compared, tabulated and statistically analysed.

Mean ATD angle in right hand male cases (42.7) is increased than controls (39.9) which is statistically significant. Mean ATD angle in left hand male cases (41.9) is increased than male controls (39.0) which is statiatically not significant.

Mean ATD angle right hand female cases (41.6) is increased than female controls (39.8) which is statistically not significant. Mean ATD angle in left hand female cases (44.3) is increased than female controls (39.1) which is statistically significant.

In combined series male and female cases on right hand (42.1) is increased than controls (39.8) which is statistically significant. On left hand combined series male and female cases (43.1) is increased than controls (39.1) which is statistically highly significant.

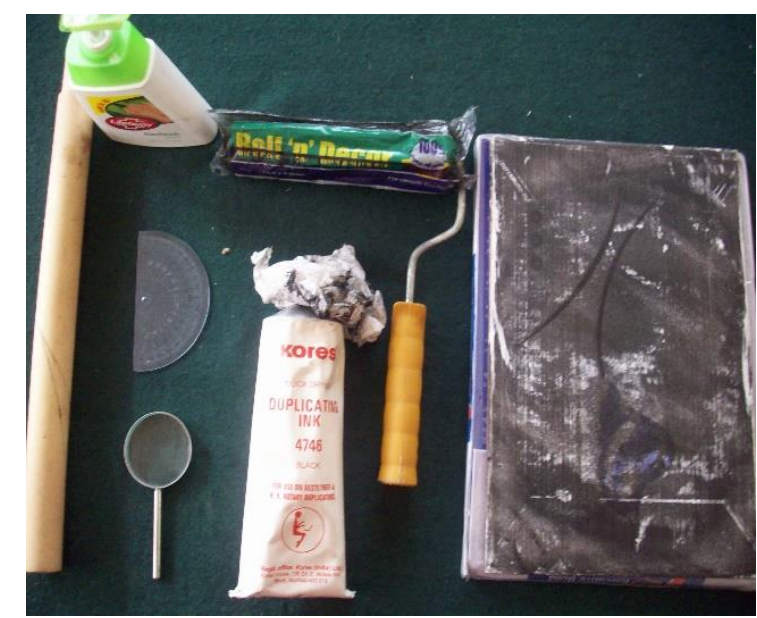

Fig. 2

Table 1: Statistical calculation of ATD angle in right and left hand of male

\begin{tabular}{|l|c|c|c|c|c|c|}
\hline \multirow{3}{*}{ ATD Angle } & \multicolumn{9}{|c|}{ Males } & \multicolumn{2}{c|}{ Controls } & \multirow{2}{*}{ P } \\
\cline { 2 - 5 } & \multicolumn{2}{|c|}{ Cases } & \multicolumn{2}{c|}{ SD } & & \\
\cline { 2 - 7 } & Mean & SD & Mean & SD & & 0.02 \\
\hline Right & 42.7 & 4.0 & 39.9 & 4.0 & 2.39 & 0.06 \\
\hline Left & 41.9 & 4.1 & 39.0 & 6.3 & 1.89 & 0.0 \\
\hline
\end{tabular}

Table 2: Statistical calculation of ATD angle in right and left hand of female

\begin{tabular}{|l|c|c|c|c|c|c|}
\hline \multirow{3}{*}{ ATD Angle } & \multicolumn{5}{|c|}{ Females } & \multicolumn{2}{c|}{ Controls } & t & \multirow{2}{*}{ Cases } & \multicolumn{2}{c|}{ Coan } & SD & & \\
\cline { 2 - 7 } & Mean & SD & Mean & & \\
\cline { 2 - 7 } & 41.6 & 6.2 & 39.8 & 4.5 & 1.22 & 0.23 \\
\hline Right & 44.3 & 8.0 & 39.1 & 5.2 & 2.84 & $0.01^{*}$ \\
\hline
\end{tabular}

Table 3: Statistical calculation of ATD angle in right and left hand of combined series of male and female epileptics and controls

\begin{tabular}{|c|c|c|c|c|c|c|}
\hline \multirow{3}{*}{ ATD Angle } & \multicolumn{6}{|c|}{ Male + Females } \\
\hline & \multicolumn{2}{|c|}{ Cases } & \multicolumn{2}{|c|}{ Controls } & \multirow[t]{2}{*}{$\mathbf{t}$} & \multirow[t]{2}{*}{$\mathbf{P}$} \\
\hline & Mean & SD & Mean & SD & & \\
\hline Right & 42.1 & 5.2 & 39.8 & 4.2 & 2.43 & $0.02 *$ \\
\hline Left & 43.1 & 6.4 & 39.1 & 5.7 & 3.30 & $0.001 *$ \\
\hline
\end{tabular}

$P$ value $<0.05$ is significant 


\section{Discussion}

In recent past, work is done to find out any assosciation of morphological and genetic characters with a number of diseases with the help of certain investigations. Dermatoglyphics is determined by polygenic inheritance and is one of such tools frequently used in scientific studies. In present study of 50 Epileptics and 50 controls, the mean ATD angle values in right and left hands of controls are 39.8 and 39.1 respectively and in cases of epilepsy these values of right and left hands are $42.1 \& 43.1$ respectively. The angle in my study in controls is narrow compared to cases in which it is increased.

A study by Nandalal. R.K Surekha ${ }^{5}$ showed the mean ATD angle values in right and left hand of controls were 39.14 and 39.22 respectively and in cases these values in right and left hands were $39.40 \& 39.64$ respectively which was statistically significant. Here the angle is increased in cases which matches with my study.

Ranganath $\mathrm{P}^{6}$ observed that ATD angle is increased in right hand female cases (41.6) than in controls not statistically significant. ATD angle is increased in both right (42.1) and left (43.1) hands of combined series of both male and female cases than controls which is statistically significant. Here also the angle is increased in cases. ATD angle is increased in left hand of male cases (41.9) than controls which is statistically not significant. ATD angle is increased in left hand female cases (44.3) than controls which is statistically significant.

Similar study on ATD angle was done in pulmonary tuberculosis by Jagadish S Chaudari ${ }^{8}$ where in it was observed that the angle was decreased in right and left hand of cases as compared to controls and the difference was statistically highly significant $(\mathrm{p}<0.001)$.

Sandeep V Pakhale ${ }^{9}$ performed same study on Branchial Asthama patients where in he found decrease in mean ATD angle in right hands of male patients than controls, which is not statistically significant. Increase in angle in left hands of male patients than controls, which is statistically not significant. Decrease in mean ATD angle in right hands of female patients than controls, which is not statistically significant. Increase in mean ATD angle in left hands of female patients than controls, not significant. Decrease in mean ATD angle in right and left hands of male patients than female patients which is statistically significant. There is decrease in angle in right and left male controls than female controls, which is statistically significant.

\section{Conclusion}

By this comparative study, dermatoglyphics parameter ATD angle can be used as screening tool for epilepsy for genetic susceptibility to disease as cost effective, non invasive harmless technique to provide early interventions. And it also proved the same in many other diseases like pulmonary tuberculosis, bronchial asthma, diabetes mellitus etc, but further evaluation using large no of cases and controls required to establish application of this data clinically because less studies done until now.

\section{References}

1. Singh IP, Bhasin MK. A manual of biological anthropology. Delhi Kamla Raj Enterprises;2004 .p.31826.

2. Bannester LH, Berry MM, Couins P, Dyson M, et al. Gray's anatomy - The anatomical basis of medicine and surgery. 38th ed. Edinburgh London: Churchill Livingstone; 2000 .p.380.

3. Nora JJ, Fraser FC. Medical genetics: Principle and practice. Philadelphia: Lea and Febiger;1974 .p.288.

4. Prathiba Ramani, Abhilash PR, Herald J. Sherlin. Conventional dermatoglyphics - Reviewed concept: A review. Int J Plasma and Biosciences. 2011 JulySept;2(3)446-458.

5. Nand Lal, RK Sureka. A study of dermatoglyphic patterns in epileptic patients. $J$ Anat Soc India. 2012;61(1):26-29.

6. Ranganath P, Rajangam S, and Kulkarni RN. Triradii of the palm in idiopathic epilepsy. $J$ Anal Soc India. 2004;53(2):22-24.

7. Priya Ranganath, RN Kulkarni, Sr Srinivasa, Sayee Rajangam. Qualitative dermatoglyphics in idiopathic epilepsy. Annals of Indian Academy of Neurology. 2004;7(1):319-321.

8. Jagadish S Chaudhari, Study of ATD Angle, Finger Ridge Count in Pulmonary Tuberculosis, International $J$ of Anatomy and Research, 2015, 3(4),1520-24. ISSN 2321- 4287.

9. Sandeep V Pakhale, Study of ATD Angle as Dermatoglyphic feature in Bronchial Asthama, International J of Health Science and Research, 2012;2(4)13-17. ISSN: 2249-9571.

How to cite this article: Goshi RC. Study of ATD angle in epileptic patients- A parameter in palmar dermatoglyphics. Ind J Clin Anat Physiol. 2018;5(3):406-409. 